\title{
$\mathrm{SAC} 305$ 솔더, $\mathrm{Sn} 58 \% \mathrm{Bi}$ 솔더 및 에폭시 $\mathrm{Sn} 58 \% \mathrm{Bi}$ 솔더와 $\mathrm{OSP}$ 표면처리된 $\mathrm{PCB}$ 기판 접합부의 미세조직 및 낙하충격시험 평가
}

\author{
김경열* · 정학산 $*$ 명우람** - 정승부 ${ }^{*}+$ \\ *성균관대학교 신소재공학부 \\ **성균관대학교 나노과학기술학과
}

\section{Microstructures and Drop Impact Test of SAC305, Sn58\%Bi and Epoxy Sn58\%Bi Solder Joint on the OSP Surface Finished PCB Substrate}

\author{
Kyung-Yeol Kim*, Haksan Jeong*, Woo-Ram Myung**, and Seung-Boo Jung*, \\ *School of Advanced Materials Science \& Engineering, Sungkyunkwan University, Suwon, 16419, Korea \\ **SKKU Advanced Institute of Nanotechnology (SAINT), Sungkyunkwan University, Suwon, 16419, Korea \\ †Corresponding author : sbjung@skku.edu
}

(Received February 26, 2018 ; Revised March 29, 2018 ; Accepted April 23, 2018)

\begin{abstract}
Lead free $\mathrm{Sn} 3.0 \% \mathrm{Ag} 0.5 \% \mathrm{Cu}$ (SAC305) solder and low temperature $\mathrm{Sn} 58 \% \mathrm{Bi}$ solder have been widely used to replace lead based solder alloys. Because Sn58\%Bi solder has poor ductility and shock absorbance ability, previous researches have tried to improve its mechanical properties by adding additional elements, reinforcements, carbon nano tube (CNT) and polymer. The bonding strength and drop impact reliability of SAC305 solder, Sn58\%Bi and epoxy contained Sn58\%Bi solder (epoxy Sn58\%Bi solder) assembled on the OSP surface finished PCB substrate were investigated using low speed shear and board drop impact tests. After soldering, Cu6Sn5 intermetallic compound (IMC) was formed in the solders and OSP surface finished PCB substrate joints. Bonding strength and drop reliability of epoxy Sn58\%Bi solder had superior mechanical properties than those of SAC305 solder and Sn58\%Bi solder. The crack in the solder joint of SAC305 after board drop impact testing takes place within the IMC layer. However, the crack at the solder joint of the $\mathrm{Sn} 58 \% \mathrm{Bi}$ after board drop impact testing occurred on the interface between IMC layer and $\mathrm{Sn} 58 \% \mathrm{Bi}$ solder and the crack in the solder joint of the epoxy Sn58\%Bi presented within the solder, respectively.
\end{abstract}

Key Words : Sn3.0\%Ag0.5\%Cu, Epoxy Sn58\%Bi, Drop impact, Bonding strength, Microstructure

\section{1. 서 론}

전자 패키징 분야에서 주로 사용되었던 유연솔더 $(\mathrm{SnPb})$ 계 솔더는 낮은 가격, 우수한 기계적 특성, 전 기적 특성 및 접합부의 신뢰성 등으로 인하여 오랫동안 사용되어 왔다 ${ }^{1)}$. 그러나 $\mathrm{Pb}$ 의 인체 유해성과 환경오염 적인 문제로 $\mathrm{Pb}$ 의 사용을 규제하는 regulation of certain hazardous substances (RoHS), waste elec- trical and electronic equipment (WEEE) 등의 환 경 규제로 인하여 무연솔더 재료의 필요성이 제기되었 다 ${ }^{2-6)} . \mathrm{SnPb}$ 계 유연솔더를 대체할 솔더로 $\mathrm{SnAgCu}$ 계, $\mathrm{SnAg}$ 계, $\mathrm{SnCu}$ 계 그리고 저융점을 갖는 $\mathrm{Sn} 58 \% \mathrm{Bi}$ 계 솔더 등 다양한 조성의 무연솔더들이 연구되어왔다 ${ }^{7-9)}$. 많은 무연솔더 합금중에서 가장 널리 상용적으로 사용 되는 $\mathrm{Sn} 3.0 \% \mathrm{Ag} 0.5 \% \mathrm{Cu}$ 솔더 $(\mathrm{SAC} 305)$ 는 상대적으 로 우수한 솔더링성과 높은 내열피로 특성을 갖고 있 다. 그러나, SAC305 솔더는 $\mathrm{Ag}$ 가 함유되어 있어 고 
가이며, $\mathrm{SnPb}$ 계 솔더에 비하여 40 도 정도의 융점이 상 승하여 종래의 유연솔더 합금에 비하여 높은 솔더링 공 정온도로 인하여 솔더계면에서 금속간화합물 (IMC)의 빠른 성장 및 부품의 열화현상을 일으킬 가능성이 높다 10). 특히, 전자패키지 부품의 경,박,단,소화를 위하여 mutil chip packages (MCP), Package-on-Package (POP) 와 같이 구조가 복잡하고 다양한 부품이 사용되면서 사 용중 혹은 제조공정중에 warpage 문제가 대두되면서 낮은 융점의 솔더재료 필요성이 대두 되었다 ${ }^{11)}$. 따라서 이러한 $\mathrm{SAC}$ 계 솔더합금의 단점인 높은 공정 온도를 해 결하기 위하여 저융점 합금인 $\mathrm{Sn} 58 \% \mathrm{Bi}$ 솔더 재료가 많이 연구되어 왔다. $\mathrm{Sn} 58 \% \mathrm{Bi}$ 솔더는 종래의 유연솔 더 $\left(\mathrm{SnPb}\right.$ 계 솔더)에 비하여 낮은 융점 $\left(139{ }^{\circ} \mathrm{C}\right)$ 을 갖고 있으며, 유연솔더에 비하여 더욱 우수한 탄성계수 및 인장강도 등을 갖는다. 또한, 저온 솔더링 공정이 가능 하므로 전자부품의 열화현상이나 warpage문제를 줄일 수 있다 ${ }^{10)}$. 그러나, $\mathrm{Sn} 58 \% \mathrm{Bi}$ 솔더의 취성으로 인하여 충격을 쉽게 완화하거나 흡수하지 못하여 기계적 특성 은 우수하지만 신뢰성이 떨어지는 단점이 존재한다 ${ }^{12)}$. 이러한 $\mathrm{Sn} 58 \% \mathrm{Bi}$ 솔더의 취성적인 성질을 향상시키기 위하여 $\mathrm{CNT}$, 강화재료, 미량의 첨가원소 혹은 에폭시 와 같은 고분자를 첨가하여 기계적 강도 및 신뢰성을 향상시키는 많은 연구가 진행되고 있다 ${ }^{14-16)}$. 본 연구에 서는 에폭시를 첨가하여 $\mathrm{Sn} 58 \% \mathrm{Bi}$ 솔더의 취성을 향상 시켜 기계적 특성을 향상하고자 하였다. 따라서, 에폭시 를 첨가한 $\mathrm{Sn} 58 \% \mathrm{Bi}$ 솔더의 향상된 특성 평가를 위해 $\mathrm{SAC} 305$ 솔더와 저융점 솔더인 $\mathrm{Sn} 58 \% \mathrm{Bi}$ 솔더, 에폭시 가 포함된 $\mathrm{Sn} 58 \% \mathrm{Bi}$ (에폭시 $\mathrm{Sn} 58 \% \mathrm{Bi}$ ) 솔더의 기계 적 특성을 저속전단시험과 낙하충격시험으로 평가하였다.

\section{2. 실험 방법}

SAC305 (TLF-204-151, TAMURA Co., Japan), Sn58\%Bi (TLF-401-11, TAMURA Co., Japan), 에폭시 Sn58\%Bi (SAM10-401-27, TAMURA Co., Japan) 총 3종류의 솔더페이스트(solder paste)를 스 크린프린팅 공정으로 organic solderability preservative(OSP) 표면처리된 $\mathrm{PCB}$ 기판위에 인쇄한 뒤 $\mathrm{re}^{-}$ flow 공정으로 솔더접합부를 형성하였다. SAC305 솔 더페이스트의 융점은 약 $220{ }^{\circ} \mathrm{C}, \mathrm{Sn} 58 \% \mathrm{Bi}$ 솔더 페이 스트의 융점은 약 $139{ }^{\circ} \mathrm{C}$ 이었다. 저속전단시험과 낙하 충격시험용 시편은 Fig. 1과 같은 공정으로 제작하였 다. 저속전단시험용 기판은 $\mathrm{FR}-4$ 기판(PCB substrate) 위에 $200 \mu \mathrm{m}$ 직경의 $\mathrm{Cu}$ pad를 형성하고 OSP로 표면 처리하였다. 솔더링공정 이전에 에탄올을 이용하여 기 판의 오염물질을 제거한 후, 스크린프린트 방법을 이용
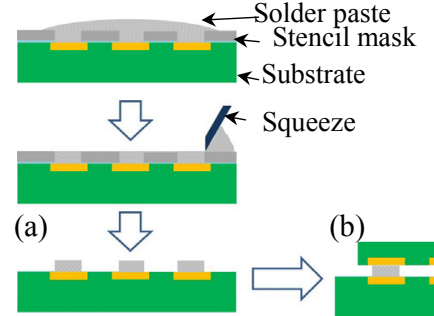

(b)
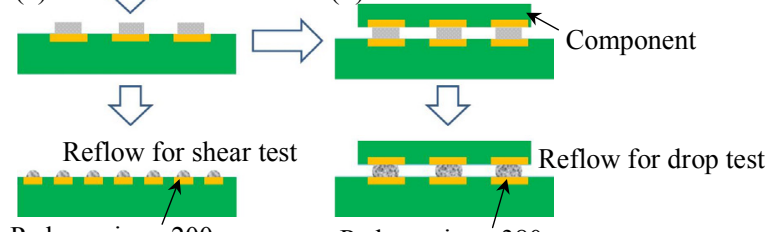

Pad opening : $200 \mu \mathrm{m}$

Pad opening : $380 \mu \mathrm{m}$

Fig. 1 Schematic of reflow process (a) shear test sample and (b) board-level drop test sample

하여 솔더 페이스트를 OSP $\mathrm{Cu}$ pad 위에 도포하였다. 도포된 솔더페이스트로 솔더볼과 솔더접합부를 형성하기 위하여 IR 리플로우 머신 (RF-430-N2, Japan Pulse Laboratory Co. Ltd., Japan)을 사용하여 5분간 리플 로우 하였다. 낙하충격시험 시편은 직경 $380 \mu \mathrm{m}$ 의 $\mathrm{Cu}$ pad에 OSP 표면처리한 FR-4 PCB 기판에 스크린프 린팅 방법으로 솔더 페이스트를 도포한 후, Fig. 1(b) 와 같이 component를 정렬한 후 리플로우를 실시하였 다. $\mathrm{Sn} 58 \% \mathrm{Bi}$ 솔더페이스트와 에폭시 $\mathrm{Sn} 58 \% \mathrm{Bi}$ 솔더 페이스트의 리플로우 최고공정온도는 Fig. 2 와 같이
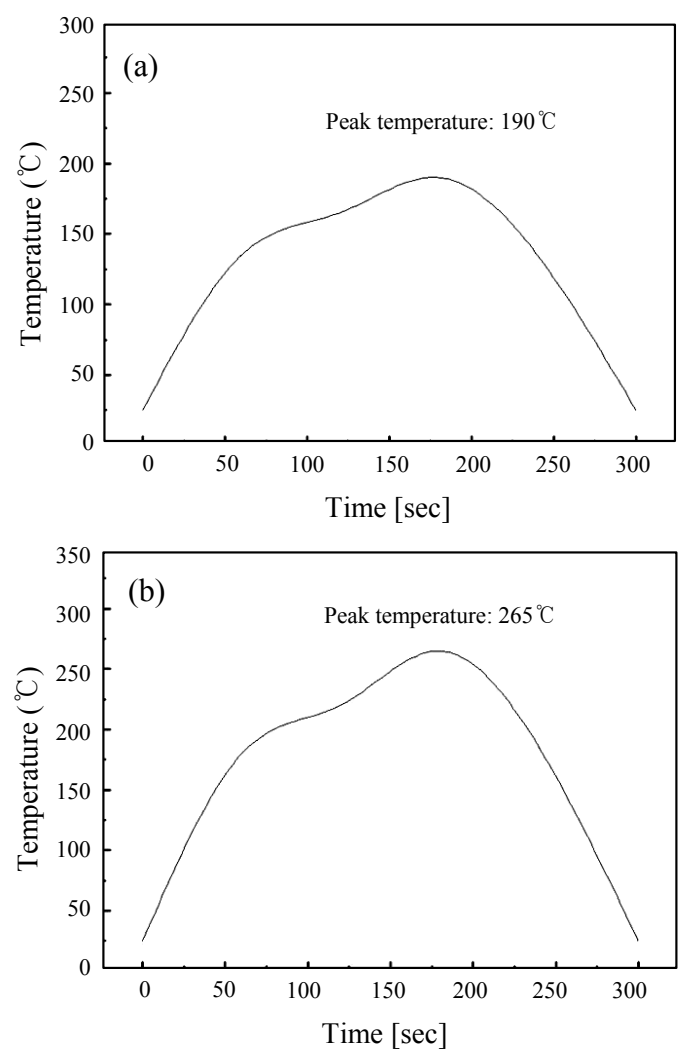

Fig. 2 Profile of reflow condition 
Table 1 JEDEC standard conditions for drop impact test (JESD22-B104-C)

\begin{tabular}{|c|c|c|}
\hline Service condition & $\begin{array}{c}\text { Acceleration } \\
\text { peak }(\mathrm{G})\end{array}$ & $\begin{array}{c}\text { Pulse durations } \\
(\mathrm{m} / \mathrm{s})\end{array}$ \\
\hline H & 2900 & 0.3 \\
\hline G & 2000 & 0.4 \\
\hline B & 1500 & 0.5 \\
\hline F & 900 & 0.7 \\
\hline A & 500 & 1.0 \\
\hline E & 340 & 1.2 \\
\hline D & 200 & 1.5 \\
\hline C & 100 & 2.0 \\
\hline
\end{tabular}

$190{ }^{\circ} \mathrm{C}, \mathrm{SAC} 305$ 솔더페이스트의 최고공정온도는 $265{ }^{\circ} \mathrm{C}$ 조건에서 5 분간 리플로우 공정으로 제조되었다. 솔더 접합부의 전단력 및 낙하신뢰성평가는 저속전단 시험과 낙하충격시험방법으로 평가하였다. 저속전단시험은 전단 시험기 (Nordson Dage Series 4000 multipurpose bond tester, Nordson Corporation, USA)를 이용 하여 JESD22-B117B 규격 ${ }^{13)}$ 에 따라 높이 $30 \mu \mathrm{m}$, 속도 $200 \mu \mathrm{m} / \mathrm{s}$ 에서 진행하였다. 또한, 본 실험에서 사용한 낙하 충격신뢰성은 낙하충격시험기 (SD-10, L.A.B. Equipment Inc., USA)를 이용하여 Table 1의 JESD22$\mathrm{B} 104 \mathrm{C}$ 규격 ${ }^{14)}$ 의 $\mathrm{F}$ 조건으로 시행하였다. 저속전단시 험 및 낙하충격시험의 모식도 및 실험조건을 Fig. 3에 나 타내었다. 저속전단시험과 낙하충격시험 후 솔더의 파단 면과 미세조직 및 화학조성은 주사전자현미경 (Hitachi, S-3000H, Japan)와 energy dispersive spectroscopy (EDS, Horiba EMAX-7021-H, England)를 사용하

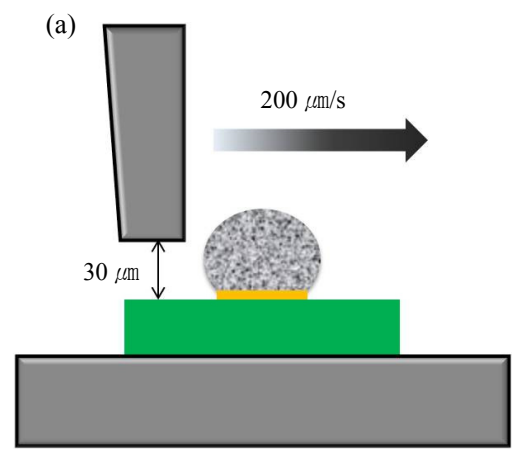

(b)

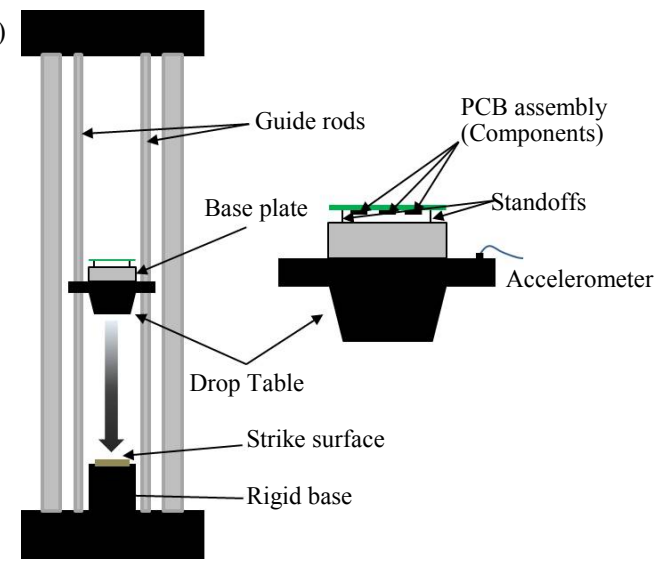

Fig. 3 Schematic of (a) shear test and (b) board-level drop test

여 분석을 실시하였다.

\section{3. 실험 고찰}

Fig. 4는 저속전단시험용 3종류의 솔더볼 시편을 리
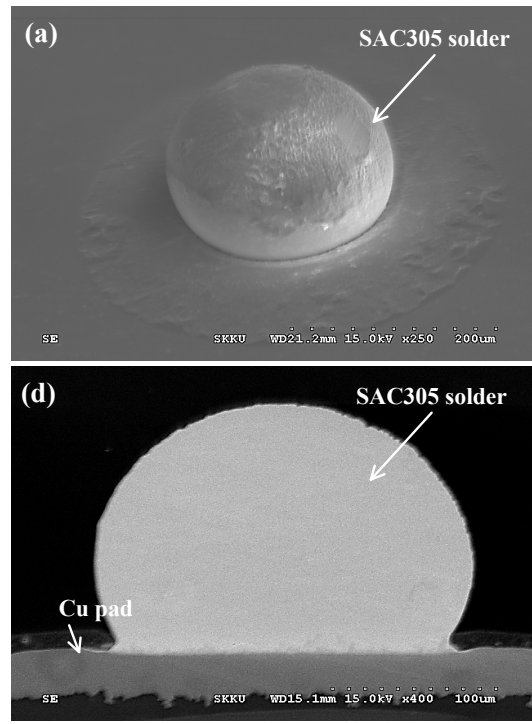
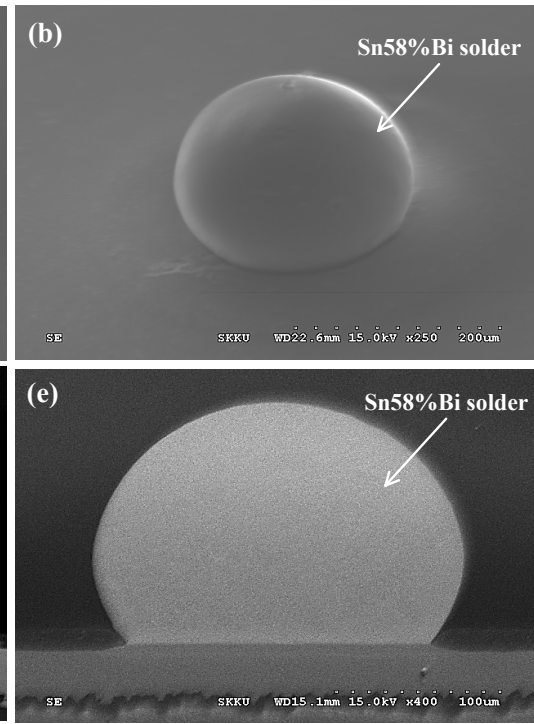
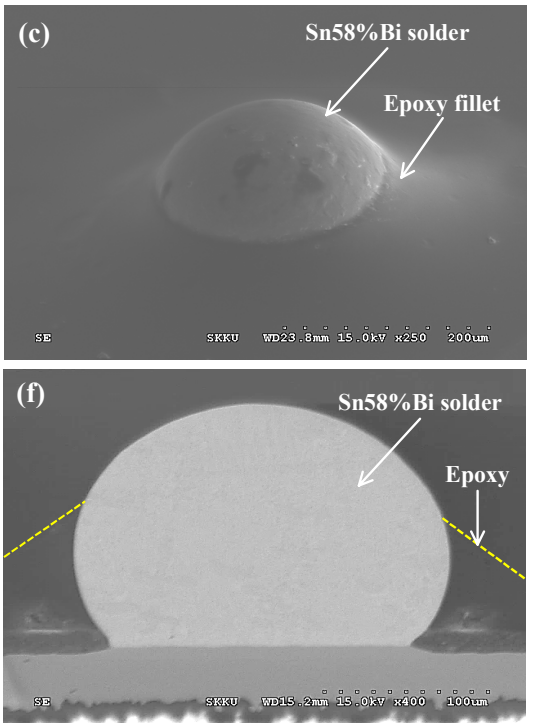

Fig. 4 SEM micrographs of the SAC305 and Sn58\%Bi solder joint after reflow process; $60^{\circ}$ tilt view of (a) SAC305 solder, (b) Sn58\%Bi solder and (c) Epoxy Sn58\%Bi solder, cross-sectional view of (d) SAC305 solder, (e) Sn58\%Bi solder and (f) Epoxy Sn58\%Bi solder 
플로우 후 $60^{\circ}$ 의 각도에서 주사전자현미경으로 관찰한 형상이다. 솔더종류와 상관없이 솔더볼들은 평균적으로 $180 \mu \mathrm{m}$ 의 직경을 갖는 것을 확인하였다. 에폭시 $\mathrm{Sn} 58 \% \mathrm{Bi}$ 솔더의 솔더볼 형상은 Fig. 4-(c)와 (f)에서 알 수 있 듯이 솔더볼 주변에 에폭시 필렛이 형성되었다. 이때, 에 폭시 필렛의 높이는 80 100 $\mu \mathrm{m}$ 이다. Fig. 5는 리플 로우 후 솔더 접합부의 단면을 관찰한 결과이다. $\mathrm{EDS}$ 분석 결과 3 종류의 솔더계면에서 형성된 금속간화합물 은 $\mathrm{Cu}_{6} \mathrm{Sn}_{5}$ 로 확인되었으며 $\mathrm{Cu}_{6} \mathrm{Sn}_{5}$ 금속간화합물 평 균두께는 $\mathrm{SAC} 305$ 솔더에서 $2.81 \mu \mathrm{m}, \mathrm{Sn} 58 \% \mathrm{Bi}$ 솔더 에서 $0.50 \mu \mathrm{m}$ 그리고 에폭시 $\mathrm{Sn} 58 \% \mathrm{Bi}$ 솔더에서는 $0.61 \mu \mathrm{m}$ 로, SAC305 솔더계면에 형성된 IMC 층이 $\mathrm{Sn} 58 \% \mathrm{Bi}$ 솔더의 계면에 형성된 것에 비하여 약 5 배정 도 두꺼운 것을 알 수 있다. SAC305 솔더는 $\mathrm{Sn} 58 \% \mathrm{Bi}$ 솔더에 비하여 $\mathrm{Sn}$ rich 솔더이기 때문에 솔더계면에서 $\mathrm{Cu}$ pad와 반응할 수 있는 $\mathrm{Sn}$ 의 양이 $\mathrm{Sn} 58 \% \mathrm{Bi}$ 솔더 에 비하여 많지만, $\mathrm{Sn} 58 \% \mathrm{Bi}$ 솔더의 $\mathrm{Sn}$ 과 $\mathrm{Bi}$ 는 유사 한 비율의 공정조직으로 존재하므로 상대적으로 $\mathrm{Cu}$ 와 반응할 수 있는 $\mathrm{Sn}$ 의 양이 적기때문에 $\mathrm{SAC} 305$ 솔더계 면에 형성된 $\mathrm{Cu}_{6} \mathrm{Sn}_{5}$ 금속간화합물의 두께는 $\mathrm{Sn} 58 \% \mathrm{Bi}$ 솔더계에 생성된 IMC 층 두께보다 더욱 두꺼웠다. Fig. 6에 3종류의 솔더에 따른 전단력 및 파괴에너지 (fracture energy)를 나타내었다. Fig. 6에서 알 수 있듯이 $\mathrm{SAC} 305, \mathrm{Sn} 58 \% \mathrm{Bi}$ 그리고 에폭시 $\mathrm{Sn} 58 \% \mathrm{Bi}$ 솔더의 전단력은 각각 $2.15 \mathrm{~N}, 2.73 \mathrm{~N}$ 및 $4.88 \mathrm{~N}$ 의 값을 가졌다. 이때, 에폭시 $\mathrm{Sn} 58 \% \mathrm{Bi}$ 솔더의 전단력이 매우 높은 것은 솔더 주위에 형성된 에폭시 필렛이 솔 더볼을 지지해주기 때문이다. 또한, 파괴에너지는 전단 시험 후 F-x 그래프를 적분을 하여 구하였다. Fig. 6(b)에서 알 수 있듯이 SAC305 솔더, $\mathrm{Sn} 58 \% \mathrm{Bi}$ 솔더 그리고 에폭시 $\mathrm{Sn} 58 \% \mathrm{Bi}$ 솔더의 파괴에너지는 각각 $0.30 \mathrm{~mJ}, 0.14 \mathrm{~mJ}, 0.61 \mathrm{~mJ}$ 로 평가되었다. $\mathrm{Sn} 58 \% \mathrm{Bi}$ 솔더의 우수한 기계적특성으로 인하여 SAC305 솔더보 다 전단력은 높지만, 취성으로 인하여 파괴에너지는 감 소했다. 그러나 에폭시가 함유된 $\mathrm{Sn} 58 \% \mathrm{Bi}$ 솔더의 파 괴에너지는 Fig. 4-(c)와 (f)에서 보여주듯이 솔더주위
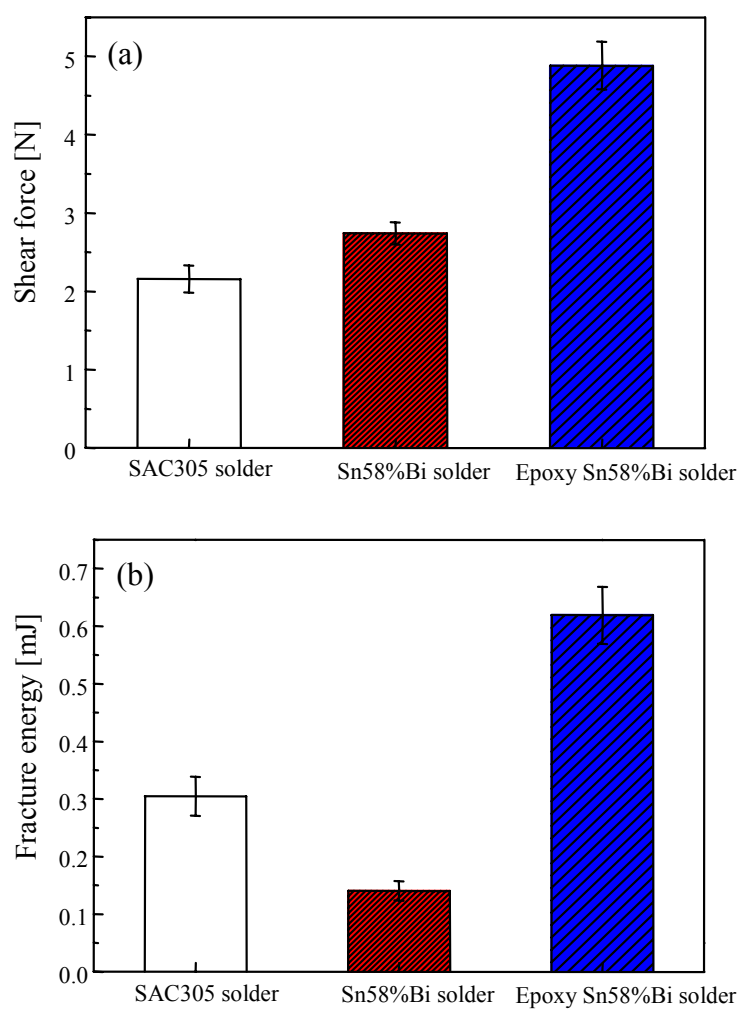

Fig. 6 (a) Shear force of solder joints and (b) Fracture energy of solder joints

에 잔존하는 에폭시 필렛이 솔더볼을 지지하기 때문에 $\mathrm{Sn} 58 \% \mathrm{Bi}$ 솔더의 취성은 개선되고 접합강도 및 파괴 에너지는 증가하였다. Fig. 7은 저속전단시험 후 솔더 의 파단면을 주사전자현미경으로 관찰한 파단면이다. Fig. 7-(a)에서 알 수 있듯이 SAC305 솔더에서는 주 로 솔더 내부에서 파단이 발생하며 확대를 하여 분석한 붉은 사각형과 같은 연성 파단면이 관찰되었다. 반면, Fig. 7-(b)의 $\mathrm{Sn} 58 \% \mathrm{Bi}$ 솔더의 파단면은 붉은 사각형 과 같이 연성과 취성조직이 혼합된 파단면이 존재하지 만 SAC305에 비하여 상대적으로 더욱 넓은 영역의 취 성 파단면이 관찰되었다. Fig. 7-(c)에서 볼 수 있듯 이, 에폭시 $\mathrm{Sn} 58 \% \mathrm{Bi}$ 솔더의 파단면에서도 붉은 사각 형과 같이 연성조직과 취성조직이 혼합되어 관찰되지만
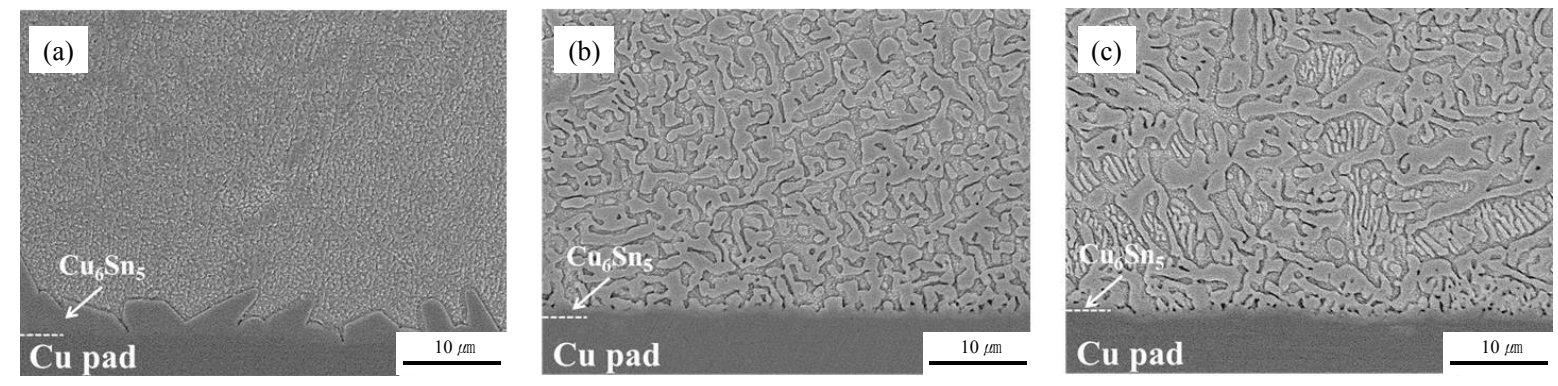

Fig. 5 Cross-sectional SEM micrographs of the solder joints; (a) SAC305, (b) Sn58\%Bi and (c) Epoxy Sn58\%Bi solder 

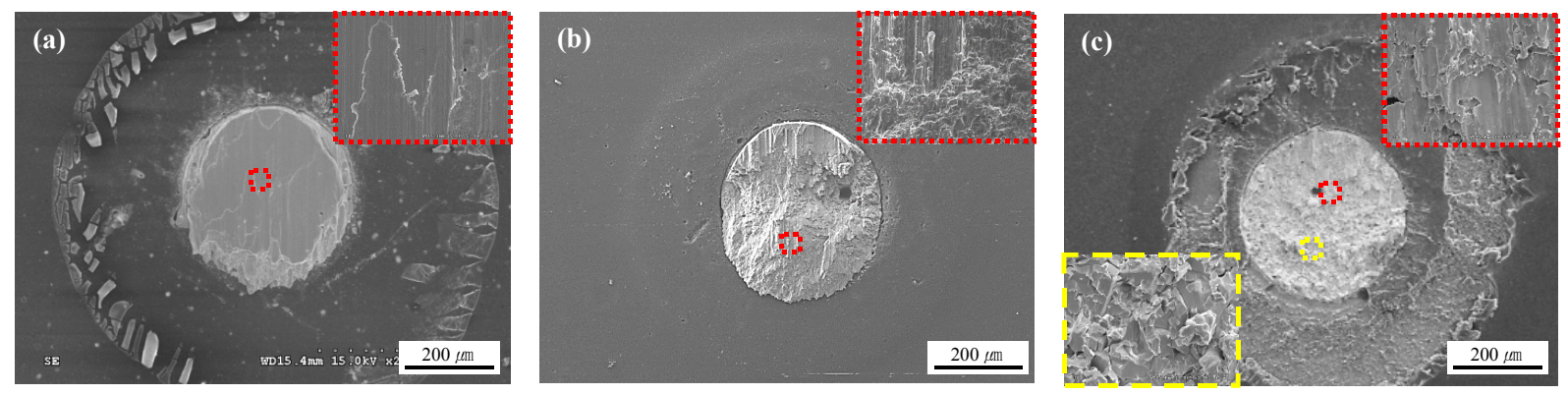

Fig. 7 Fracture surfaces after shear test (a) SAC305 solder, (b) Sn58\%Bi solder and (c) Epoxy Sn58\%Bi solder

주변에 잔존하는 에폭시 필렛들이 솔더볼과 함께 lift될 때 노란색 사각형과 같이 취성 파단면이 관찰되었다. 이러한 에폭시 필렛의 lift때문에 에폭시 $\mathrm{Sn} 58 \% \mathrm{Bi}$ 솔 더는 상대적으로 높은 전단력과 높은 파괴에너지를 가 지는 것으로 사료된다. 따라서, SAC305 솔더는 전반 적인 연성 파단때문에 $\mathrm{Sn} 58 \% \mathrm{Bi}$ 솔더보다 높은 파괴 에너지를 나타내었으며, 에폭시가 함유된 $\mathrm{Sn} 58 \% \mathrm{Bi}$ 솔 더가 상대적으로 높은 접합강도와 파괴에너지를 갖는 것은 전단시험시 응력이 에폭시로 분산되기 때문으로 사료된다 ${ }^{15-17)}$. 또한, $\mathrm{Sn} 58 \% \mathrm{Bi}$ 솔더에 취성 파단면이 발생하고, SAC305 솔더에 비하여 낮은 파괴에너지를 갖는 것은 $\mathrm{Sn} 58 \% \mathrm{Bi}$ 솔더계면에 형성된 $\mathrm{Bi}$ rich 조직 이 상대적으로 $\mathrm{SAC} 305$ 의 $\mathrm{Sn}$ rich상에 비해 더욱 취 성적인 특성을 갖기 때문이다 ${ }^{18)}$. Fig. 8은 SAC305 솔더, $\mathrm{Sn} 58 \% \mathrm{Bi}$ 솔더, 에폭시 $\mathrm{Sn} 58 \% \mathrm{Bi}$ 솔더와 $\mathrm{OSP}$ 표면처리된 $\mathrm{PCB}$ 기판을 솔더링한 시편의 board level drop impact test를 각 시편당 3회씩 실시한 뒤 평균 값을 나타낸 그래프다. $\mathrm{SAC} 305$ 솔더, $\mathrm{Sn} 58 \% \mathrm{Bi}$ 솔 더, 에폭시 $\mathrm{Sn} 58 \% \mathrm{Bi}$ 솔더의 낙하충격횟수는 각각 95 회, 3회, 185 회의 값을 가졌다. 낙하충격신뢰성은 Fig. 6-(a)에서 알 수 있듯이 전단력이 높은 $\mathrm{Sn} 58 \% \mathrm{Bi}$ 솔 더가 SAC305 솔더에 비하여 높은 낙하충격횟수를 나 타낼 것을 예상했으나, Fig.6-(b)의 파괴에너지 경향과 일치하였다. 즉, 파괴에너지는 재료의 파괴에 필요한 전체 에너지를 의미하고 낙하충격시 재료가 파단되기까지

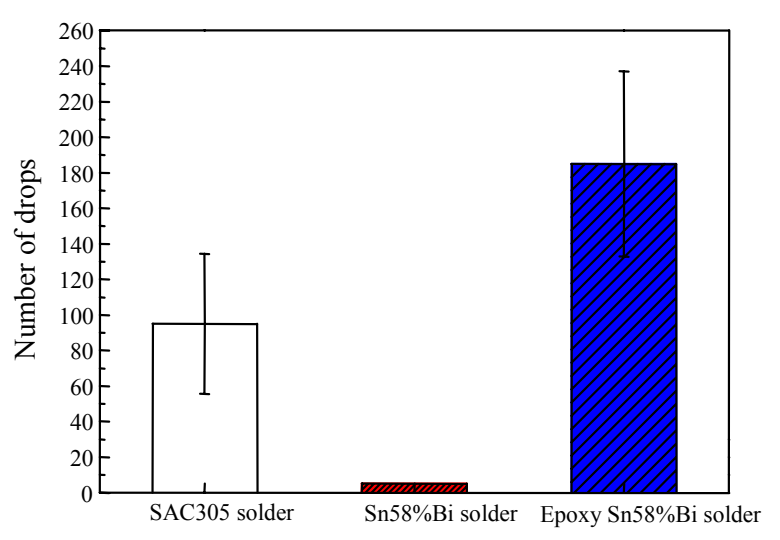

Fig. 8 Average number of drops to failure

내부에 축적할 수 있는 에너지량으로 솔더의 신뢰성 평가 가 가능하다. 본 연구에서는 $\mathrm{Sn} 58 \% \mathrm{Bi}$ 솔더, $\mathrm{SAC} 305$ 솔더 그리고 에폭시 $\mathrm{Sn} 58 \% \mathrm{Bi}$ 솔더 순서로 증가하며 솔더의 파괴에너지 값과 낙하충격 시험의 경향성은 일 치하였다. Fig. 9는 낙하충격시험 후 솔더접합부의 파 단면을 관찰한 결과이다. Fig. 9-(a)는 SAC305 솔더 의 파단면으로, 파단은 주로 $\mathrm{Cu}_{6} \mathrm{Sn}_{5}$ 로 이루어진 금속 간화합물 층과 $\mathrm{Cu}$ pad의 계면에서 발생하는 것을 확 인하였다. 한편 $\mathrm{Sn} 58 \% \mathrm{Bi}$ 솔더와 에폭시 $\mathrm{Sn} 58 \% \mathrm{Bi}$ 솔더는 Fig. 9-(b)와 (c)에서와 같이 $\mathrm{Sn} 58 \% \mathrm{Bi}$ 솔더 에서는 금속간화합물과 솔더사이의 계면에서 파단이 발 생하고, 에폭시 $\mathrm{Sn} 58 \% \mathrm{Bi}$ 솔더에서는 솔더내부에서 크 랙이 발생하였다. $\mathrm{Ha}$ 등 $^{19-21)}$ 의 연구보고 등에 의하면
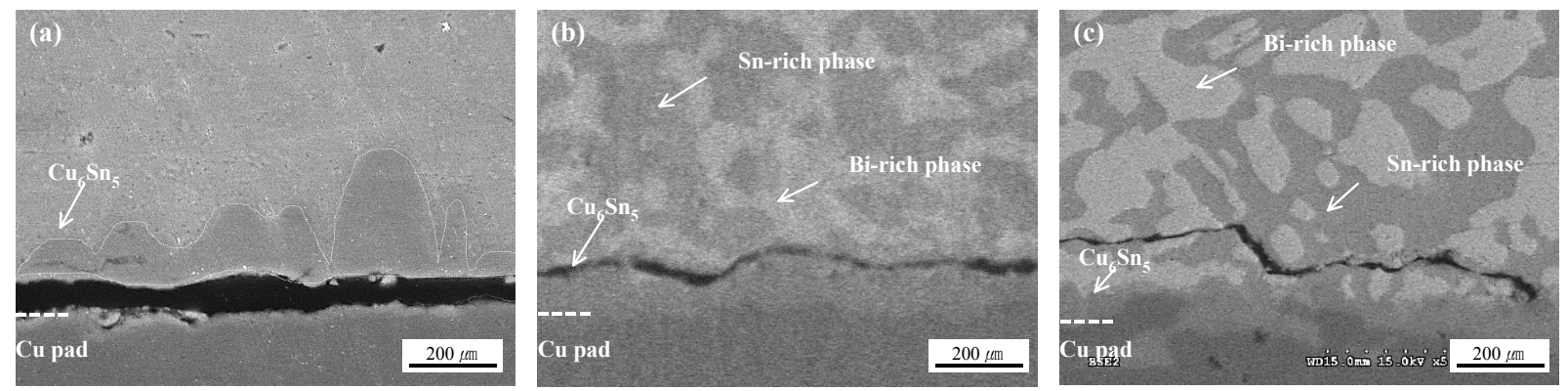

Fig. 9 Cross-sectional SEM micrographs after drop test (a) SAC305 solder, (b) Sn58\%Bi solder and (c) epoxy Sn58\%Bi solder 
일반적으로 금속간화합물이 임계두께 이상으로 성장할 때 $\mathrm{IMC}$ 층에서 입계파단이 주로 발생하여 접합강도는 감소한다. 따라서, 본 연구의 $\mathrm{SAC} 305$ 와 $\mathrm{OSP} \mathrm{PCB}$ 기 판의 계면에 생성된 $\mathrm{IMC}$ 층은 $\mathrm{Sn} 58 \% \mathrm{Bi}$ 와 $\mathrm{OSP} \mathrm{PCB}$ 기판의 계면에 생성된 IMC 층의 두께보다 5 배정도 두 꺼웠기 때문에 IMC 층에서 파단이 발생하였다.

\section{4. 결 론}

본 연구에서는 $\mathrm{SAC} 305$ 솔더, $\mathrm{Sn} 58 \% \mathrm{Bi}$ 솔더 그리 고 에폭시가 함유된 $\mathrm{Sn} 58 \% \mathrm{Bi}$ 솔더를 OSP 표면처리 된 $\mathrm{Cu}$ pad 위에 screen printing으로 인쇄하고 리플 로우 공정으로 솔더볼 및 솔더접합부를 형성하였다. 3 가지 종류의 솔더시편은 저속전단시험방법으로 전단력 을 평가하였고, $\mathrm{PCB}$ component 부품을 실장하여 낙 하충격시험법으로 솔더접합부의 충격신뢰성을 평가하였 다. 리플로우 후, 에폭시 유무와 관계없이 3 종류의 솔 더볼 직경은 약 $180 \mu \mathrm{m}$ 이며, 3종류의 솔더와 OSP 표 면처리된 $\mathrm{Cu} \mathrm{pad}$ 의 계면에는 $\mathrm{Cu}_{6} \mathrm{Sn}_{5}$ 금속간화합물이 형성되었다. 저속전단시험에서 $\mathrm{SAC} 305$ 솔더, $\mathrm{Sn} 58 \% \mathrm{Bi}$ 솔더 그리고 에폭시가 함유된 $\mathrm{Sn} 58 \% \mathrm{Bi}$ 솔더 순서로 전단력이 증가하였다. 파괴에너지는 $\mathrm{Sn} 58 \% \mathrm{Bi}$ 솔더, $\mathrm{SAC} 305$ 솔더 그리고 에폭시가 함유된 $\mathrm{Sn} 58 \% \mathrm{Bi}$ 솔더 순서로 증가하였다. 저속전단시험 후 관찰한 SAC305 솔더의 파단면은 연성파괴 파면이 주로 관찰되지만, $\mathrm{Sn}^{-}$ $58 \% \mathrm{Bi}$ 솔더의 파단면은 취성파괴와 연성파괴가 혼합된 판단면이 관찰되었다. 또한, 에폭시가 함유된 $\mathrm{Sn} 58 \% \mathrm{Bi}$ 파단면도 취성파괴와 연성파괴가 혼합된 조직으로 관찰 되지만 솔더볼 주위에 형성된 에폭시 필렛이 전단응력 을 분산시키고 기계적 특성을 향상시켜 높은 전단력과 파괴에너지가 나타나는 것으로 사료된다. 낙하충격시험 결과, $\mathrm{Sn} 58 \% \mathrm{Bi}$ 솔더, $\mathrm{SAC} 305$ 솔더 그리고 에폭시가 첨가된 $\mathrm{Sn} 58 \% \mathrm{Bi}$ 솔더 순으로 낙하충격 신뢰성이 증 가하는 것은 솔더 주위에 형상된 에폭시의 필렛이 응력 을 분산하여 충격을 흡수하기 때문이며, 파괴에너지의 경향과 일치하였다. 낙하충격시험 후 단면분석에서 알 수 있듯이 SAC305 솔더접합부의 파단면은 $\mathrm{Cu}_{6} \mathrm{Sn}_{5}$ 금 속간화합물 층에서 주로 파단이 발생하였고, $\mathrm{Sn} 58 \% \mathrm{Bi}$ 솔더접합부는 $\mathrm{Cu}_{6} \mathrm{Sn}_{5}$ 금속간화합물과 솔더사이의 계면 에서 발생하며 에폭시 $\mathrm{Sn} 58 \% \mathrm{Bi}$ 솔더에서는 솔더내부 에서 주로 크랙이 발생하였다.

ORCID: Kyung-Yeol Kim: https://orcid.org/0000-0001-9768-2949 ORCID: Haksan Jeong: https://orcid.org/0000-0003-4823-284X ORCID: Seung-Boo Jung: https://orcid.org/0000-0002-7360-9859

\section{References}

1. J.W. Yoon and S.B. Jung, Investigation of interfacial reactions between $\mathrm{Sn}-5 \mathrm{Bi}$ solder and $\mathrm{Cu}$ substrate, $J$. Electron. Mater., 359 (1-2) (2003), 202-208 https://doi.org/10.1016/S0925-8388(03)00291-3

2. J.W. Yoon, C.B. Lee and S.B Jung, Growth an Intermetallic Compound Layer with $\mathrm{Sn}-3.5 \mathrm{Ag}-5 \mathrm{Bi}$ on $\mathrm{Cu}$ and $\mathrm{Ni}-\mathrm{P} / \mathrm{Cu}$ during Aging Treatment, J. Electron. Mater., 32 (11) (2003), 1195-1202 https://doi.org/10.1007/s11664-003-0011-8

3. J.W. Yoon, W.C. Moon and S.B Jung, Interfacial reaction of ENIG/Sn-Ag-Cu/ENIG sandwich solder joint during isothermal aging, Microelectron. Eng., 83 (11-12) (2006), 2329-2334

https://doi.org/10.1016/j.mee.2006.10.027

4. J.J. Soh, D.S. Shim and W.B. Byung, Technical trend of Restriction of Hazardous Substances Directive(RoHS), Conference of The Korean Institute of Electrical Engineering, (2009), 1289-1290

5. J. Glazer, Microstructure and Mechanical Properties of $\mathrm{Pb}$-Free Solder Alloys for Low-Cost Electronic Assembly, A Review, J. Electron. Mater., 23 (8) (1994), 693-700 https://doi.org/10.1007/BF02651361

6. S.W. Kim, J.W.Yoon and S.B. Jung, Interfacial Reactions and Shear Strengths between Sn-Ag-based Pb-Free Solder Balls and $\mathrm{Au} / \mathrm{EN} / \mathrm{Cu}$ metallization, J. Electron. Mater., 33 (10) (2004), 1182-1189 https://doi.org/10.1007/s11664-004-0121-y

7. T.Y Lee, W,J, Choi, K.N. Tu and J.W. Jang, Morphology, kinetics, and thermodynamics of solid-state aging of eutectic $\mathrm{SnPb}$ and $\mathrm{Pb}$-free solders $(\mathrm{Sn}-3.5 \mathrm{Ag}, \mathrm{Sn}-3.8 \mathrm{Ag}-0.7 \mathrm{Cu}$ and $\mathrm{Sn}-0.7 \mathrm{Cu}$ ) on $\mathrm{Cu}$, J. Mater Res., 17 (2) (2002), 291301

https://doi.org/10.1557/JMR.2002.0042

8. S.O. Ha, S.S. Ha, J.B. Lee, J.W. Yoon, J.H. Park, Y.C. Chu, J.H. Lee, S.J. Kim and S.B Jung, Drop reliability evaluation of Sn-3.0Ag-0.5Cu solder joint with OSP and ENIG surface finishes, J. Microelectron. Package Soc., 16 (1) (2009), 33-38

9. J.W. Yoon, C.B. Lee and S.B. Jung, Interfacial Reactions Between Sn-58 mass\%Bi Eutectic Solder and $(\mathrm{Cu}$, Electroless Ni-P/Cu) Substrate, Mater. Trans., 43 (8) (2002), 1821-1826

10. C. Wu, J. Shen, C. Peng, Effects of trace amounts of rare earth additions on the microstructures and interfacial reactions of $\mathrm{Sn} 57 \mathrm{Bi} 1 \mathrm{Ag} / \mathrm{Cu}$ solder joints, $J$. Mater. Sci., Mater. Electron., 23 (1) (2012), 14-21 https://doi.org/10.1007/s10854-011-0383-0

11. J. Wang, L. Wen, J. Zhou, M. Chung, Mechanical properties and joint reliability improvement of Sn-Bi alloy, 13th Electronics Packaging Technology Conference, (2011), 492-496 
https://doi.org/10.1109/EPTC.2011.6184470

12. C. Fuchs, T. Schreck, M. Kaloudis, Interfacial reactions between $\mathrm{Sn}-57 \mathrm{Bi}-1 \mathrm{Ag}$ solder and electroless Ni-P/immersion $\mathrm{Au}$ under soild-state aging, J. Mater. Sci., 47 (9) (2012), 4036-4041 https://doi.org/10.1007/s10853-012-6257-x

13. JEDEC Solid State Technology Association, JESD22B117B "Solder Ball Shear" (2014)

14. JEDEC Solid State Technology Association, JESD22B104C "Mechanical Shock" (2004)

15. J. Kim, W.R. Myung and S.B Jung, Effect of Aging treatment and Epoxy on Bonding Strength of Sn-58Bi solder and OSP-finished PCB, J. Microelectron. Packag. Soc., 21 (4) (2014), 97-103 https://doi.org/10.6117/kmeps.2014.21.4.097

16. W.R. Myung, Y. Kim, K.Y. Kim and S.B. Jung, Drop Reliability of Epoxy-contained Sn-58 wt.\%Bi Solder Joint with ENIG and ENEPIG Surface Finish Under Temperature and Humidity Test, J. Electron. Mater., 45 (7) (2016), 3651-3658

https://doi.org/10.1007/s11664-016-4517-2
17. W.R. Myung, Y. Kim and S.B. Jung, Mechanical property of the epoxy-contained Sn-58Bi solder with OSP surface finish, J. Alloys Compd., 615 (1) (2014), S411- 417 https://doi.org/10.1016/j.jallcom.2014.01.078

18. J.S. Hwang, Environment-friendly electronics, lead-free technology. Electrochemical Publications Limited, (2001)

19. S.S. Ha, J.W. Kim, J.H, C, W.C. Moon, T.H. Hong, C.S. Yoo, J.H. Moon and S.B. Jung, Thermo-Mechanical Reliability of Lead-Free Surface Mount Assemblies for Auto-Mobile Application, Journal of KWJS, 24 (6) (2006), 21-27

20. Y. Y. Wei and J. G. Duh, Effect of thermal ageing on (Sn-Ag, Sn-Ag- Zn)/PtAg, Cu/A12O3 solder joints, $J$. Mater. Sci. Mater. El., 9 (5) (1998), 373-381 https://doi.org/10.1023/A:1008940311075

21. S. Choi, T. R. Bieler, J. P. Lucas and K. N. Subramanian, Characterization of the growth of intermetallic interfacial layers of $\mathrm{Sn}-\mathrm{Ag}$ and $\mathrm{Sn}-\mathrm{Pb}$ eutectic solders and their composite solders on $\mathrm{Cu}$ substrate during isothermal long-term aging, J. Electron. Mater., 28 (11) (1999), 1209-1215

https://doi.org/10.1007/s11664-999-0159-y 